\title{
COMMUNICATIONS
}

\section{PROGNOSIS IN CASES OF STRABISMUS WITH SPECIAL REFERENCE TO ORTHOPTIC TREATMENT*}

\author{
BY \\ T. KEITH LYLE AND JILL FOLEY \\ From the Orthoptic Department of Moorfields Eye Hospital \\ (High Holborn Branch)
}

WHEN orthoptic treatment was first practised it was thought that, if it were applied in cases of non-paralytic strabismus where there was geod visual acuity in each eye, restoration of normal binocular function would invariably result. In the early 1930s it was not unusual for children suffering from squint to be subjected to countless sessions of treatment with reflecting stereoscopes in the hope of establishing fusion. It was not until Chavasse (1939) published his theories with regard to the binocular reflexes and their development, that the true limitations of orthoptic treatment became more widely recognized. The important fact then emerged that, the earlier the onset of a constant strabismus and the longer the interval of time before corrective treatment is carried out, the less likely is it that normal binocular function will be restored, no matter how much orthoptic treatment is given.

Experience with a large series of cases of strabismus and the study of the work of Chavasse have taught us that in certain cases binocular single vision cannot be attained whatever the treatment, while in others, provided the correct treatment is given, the restoration of binocular single vision is certain. Thus, statistics regarding the results of treatment in terms of binocular function are quite meaningless unless they contain information about the types of case under review. The correct treatment varies according to the type of case; it may consist merely of appropriate spectacles (with or without the assistance of orthoptic treatment), or of surgical treatment (with or without the assistance of spectacles and orthoptic treatment), or of orthoptic treatment only. Despite these facts, in many clinics a routine course of orthoptic treatment is still recommended and carried out indiscriminately in all cases of non-paralytic strabismus. The result is that a large percentage of patients treated by orthoptic measures fail to regain normal binocular function. The conclusion is drawn that in these cases orthoptic treatment has failed, as indeed it has, but the failure is due to its employment where it was not indicated.

After studying the history of a case of strabismus and after carrying out a thorough examination, it should be possible in most instances to decide 
what sort of treatment is needed and to give a fairly accurate prognosis with regard to the possibility of restoring binocular single vision. Admittedly, in young infants too uncooperative for examination on a major amblyoscope, the prognosis may have to be guarded, but even then, with a knowledge of the case history and the family history and a simple clinical examination, a reasonably accurate prognosis can often be given.

It is our aim in this article to review some of the factors concerned in prognosis and to consider how appropriate treatment can be planned with special reference to the place of orthoptic measures.

\section{(A) NON-PARALYTIC STRABISMUS}

\section{NON-PARAlYTiC CONVERGENT STRABiSMUS*}

Perhaps it is chiefly in convergent strabismus that the selection of cases suitable for orthoptic treatment appears to present the most difficulty. It was therefore decided to submit to critical analysis a series of unselected cases of non-paralytic convergent strabismus in children under 10 years of age in order to find out how and where orthoptic treatment appeared to have helped in establishing normal binocular function, and where it had apparently been a waste of time and effort.

An analysis of 287 consecutive cases of non-paralytic convergent strabismus treated at the High Holborn branch of the Moorfields Eye Hospital during the years 1950 to 1954 showed that binocular single vision was restored in 98 cases ( 34 per cent.) and that 189 cases (66 per cent.) remained non-binocular.

These bare facts, however, do not tell us in which particular type of case a binocular result was obtained and in which type of case there was failure to establish binocular vision. Furthermore, these figures give no hint as to how such factors as the age at onset of squint and the interval between the onset of squint and the treatment that finally corrected it may have affected the prognosis.

If we divide the 287 cases into accommodative and non-accommodative, we see at once how the prognosis differs (Table I).

TABLE I

NON-PARALYTIC CONVERGENT STRABISMUS

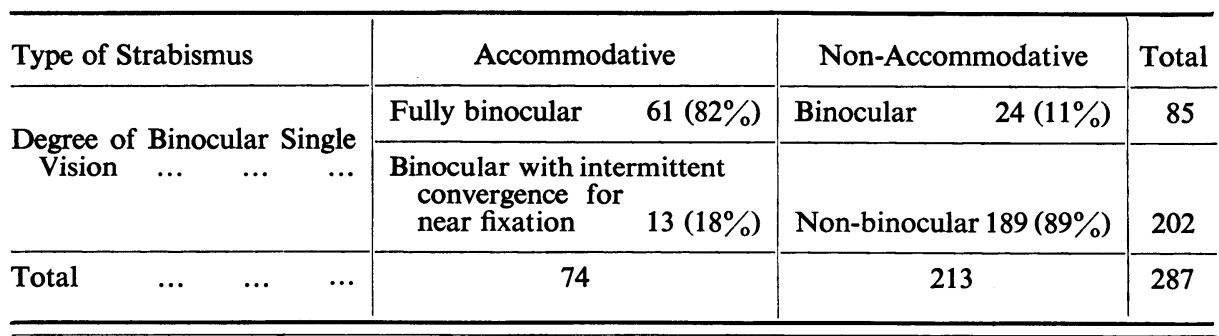

* We have used the term non-paralytic rather than concomitant because few cases of convergent strabismus are strictly concomitant, a concomitant strabismus being one in which the angle of deviation remains the same whichever eye is fixing and in whichever direction the eyes are looking. 
(1) Non-paralytic Accommodative Convergent Strabismus (74 cases: Tables II and IIA)

"It seems highly probable that if glasses were prescribed for the infant immediately and as a matter of extreme urgency at the first momentary glide of the eye, the problem of accommodational squint, both in its visual and aesthetic aspects, would disappear. Operations would not be necessary. Multitudes of eyes would be saved for acute vision against the possible loss, by accident or disease, of their fellows. A heavy financial burden would thus be lifted from the community."

So wrote Chavasse (1939), and there is no doubt that his words are very largely true.

Accommodative strabismus rarely appears before the development of the frontal accommodation-convergence reflex, and its incidence is highest in children of the 3-year age group. At this age a child begins to take an increasing interest in small objects situated near at hand and, if he is moderately hypermetropic and in consequence has to exercise considerable accommodation in order to see clearly, he may over-converge when he accommodates (since accommodation and convergence act synergically). Although intermittent in the early stages, an accommodative strabismus in which an occasional but marked convergence appears is often more noticeable at the onset than is a strabismus of the non-accommodative type in which a small static deviation may be overlooked for many months or even years. If a full correction of the refractive error is prescribed at the earliest opportunity, the visual axes are usually restored to parallelism, harmony between accommodation and convergence is re-established, and amblyopia and loss of binocular function are rare. In neglected cases, however, correction of the refractive error may merely reduce but not eliminate the deviation and the therapeutic problem is more complex.

The restoration of binocular single vision in the 74 cases of accommodative strabismus under consideration suggests that there is little to criticize in the treatment they received, although the part played by orthoptic treatment in the results achieved may be open to inquiry.

These 74 cases may be sub-divided into three groups (Tables II and IIA, overleaf):

(a) Fully Accommodative Strabismus (33 cases).-Here there was no deviation for near or for distance when glasses were worn which corrected the hypermetropia, but there was a convergent deviation without glasses.

(b) Accommodative Strabismus with Convergence Excess (21 cases).-Here there was no deviation for distance when glasses were worn which corrected the hypermetropia, but there was a constant deviation for near, and a constant convergent strabismus without glasses.

(c) Partially Accommodative Strabismus (20 cases).- - Here there was a constant convergent deviation, the angle of which was greater for near fixation. The angle of deviation was diminished with glasses. 
There appeared to be little difference in the aetiology of the three types of accommodative strabismus. In the majority of cases the onset was intermittent with no obvious cause. In all three groups the average age at onset of strabismus was just over 3 years, and the average interval between the onset of the strabismus and the correction of the refractive error was not less than about one year (Table II).

TABLE II

ACCOMMODATIVE CONVERGENT STRABISMUS

\begin{tabular}{|c|c|c|c|}
\hline Type of Strabismus & $\begin{array}{c}\text { Fully } \\
\text { Accommodative (33) }\end{array}$ & $\begin{array}{l}\text { Convergence } \\
\text { Excess (21) }\end{array}$ & $\begin{array}{c}\text { Partially } \\
\text { Accommodative (20) }\end{array}$ \\
\hline $\begin{array}{l}\text { Average age of Patients } \\
\begin{array}{ccc}\text { (yrs) } \ldots & \ldots\end{array}\end{array}$ & $5 \cdot 9$ & 6 & 6 \\
\hline $\begin{array}{c}\text { Average Age at } \\
\text { of Squint (yrs) }\end{array}$ & $3 \cdot 1$ & $3 \cdot 6$ & $3 \cdot 2$ \\
\hline $\begin{array}{l}\text { Average Interval be- } \\
\text { tween Onset of Squint } \\
\text { andCorrection of Re- } \\
\text { fractive Error (yrs)... }\end{array}$ & 2 & 1 & 1 \\
\hline
\end{tabular}

(a) Fully Accommodative Strabismus (33 cases).-Restoration of full binocular single vision was effected in ten of the 33 cases by correction of the refractive error alone without the aid of orthoptic treatment. Of the remaining 23 cases in which orthoptic treatment was given, there was no appreciable loss of binocular function (with the exception of three cases in which amblyopia had first to be rectified by occlusion of the non-squinting eye). If orthoptic treatment had been omitted, there is no reason to suppose that the ultimate result would have been less successful provided adequate attention was given to the prescription and wearing of glasses.

It is generally agreed that a child with a fully accommodative strabismus should be taught to relax his accommodation when not wearing glasses, thus establishing binocular single vision at the expense of clear vision. Much time is often spent in teaching such a child relative accommodation (i.e. clearing the image whilst maintaining single vision). In a child with a refractive error of about $+3 \mathrm{D}$ sph. or less, whose refractive error is likely to decrease with age, binocular single vision without glasses will no doubt be achieved without the aid of the synoptophore, bar-reader, and other orthoptic apparatus provided the strength of the glasses is gradually reduced as and when indicated.

In a child with hypermetropia of more than about $+3 \mathrm{D}$ sph. or with considerable astigmatism, who is likely to continue wearing glasses indefinitely, it is questionable whether the time that is often spent in teaching him to bar-read and to improve binocular visual acuity without glasses (or with a reduced correction) is really justifiable. It is usually preferable to give the patient a few lessons on how to relax accommodation and convergence 
without glasses so as to enable him to maintain a reasonable ocular appearance when he is unable or does not wish to wear glasses.

(b) Accommodative Strabismus with Convergence Excess (21 cases).-In the convergence excess and partial accommodative type of strabismus, the child may continue to over-converge for near vision even after prolonged orthoptic treatment. Although in the passage of time we have found that in some cases this over-convergence may tend to disappear, this is the exception rather than the rule.

Opinions differ as to the treatment of children with accommodative strabismus of this type, and there are three current methods:

(i) Full correction of the refractive error combined with orthoptic treatment. Supporters of this method believe that in time the relationship between accommodation and convergence will right itself.

(ii) Bifocal spectacles. This method is rarely used at this hospital and we have therefore scant experience of its value, but we have often observed that children who are yearing bifocals frequently fail to accept the extra "plus correction" and tend to read through the distance part of the glasses, thus defeating the purpose of the bifocal glasses. It is of course an obvious fact that bifocal glasses are useless unless the extra "near-vision" addition does actually secure binocular fixation.

(iii) Surgery, usually after a trial period of orthoptic treatment. This in our experience has been the most satisfactory method. It has been suggested that operation may cause consecutive divergence in later life, but this is unlikely provided binocular functions are strong.

In this series of cases, patients who had orthoptic treatment, particularly when combined with operation, show better results than those who did not. Although there is no doubt that in these cases orthoptic treatment played a useful part in re-establishing a normal relationship between accommodation and convergence, it is not possible to lay down hard and fast rules as to its use and each case should be judged on its merits. Insufficient time has elapsed to consider the possibility of consecutive divergence, but early results show no tendency to divergence. Indeed one would not expect divergence to occur in view of the good binocular function present. Reexamination of patients in a few years time may give valuable information as to the advisability of surgery in this type of case.

(c) Partially Accommodative Strabismus (20 cases).-The importance of dealing immediately with the refractive error is shown in the cases of partially accommodative strabismus in which optical treatment has failed to eliminate the deviation entirely or has been inadequately carried out, for it is probable that many of the cases in this group were originally cases of fully accommodative strabismus or of accommodative strabismus with convergence excess. Although the deterioration of binocular function which occurred in ten cases was not as severe as is found in neglected cases of non-accommodative 
convergent strabismus, it was sufficient to complicate and lengthen the treatment.

Operation is invariably necessary in this type of strabismus. Although full binocular single vision was restored in five cases by surgery alone, orthoptic treatment was undoubtedly of value in consolidating the results of the operation in fourteen cases.

In one case binocular single vision was restored by orthoptic treatment alone.

Table IIA summarizes the results of treatment in all three groups:

TABLE IIA

RESULTS IN 74 CASES OF ACCOMMODATIVE CONVERGENT STRABISMUS

\begin{tabular}{|c|c|c|c|c|c|c|}
\hline \multirow{2}{*}{ Treatment } & \multicolumn{3}{|c|}{$\begin{array}{l}\text { Restoration of Full Binocular } \\
\text { Single Vision }\end{array}$} & \multicolumn{2}{|c|}{$\begin{array}{l}\text { Restoration of Binocular } \\
\text { Single Vision with Inter- } \\
\text { mittent Convergence for } \\
\text { Near }\end{array}$} & \multirow{2}{*}{ Total } \\
\hline & $\begin{array}{c}\text { Fully } \\
\text { Accommo- } \\
\text { dative }\end{array}$ & $\begin{array}{c}\text { Conver- } \\
\text { gence } \\
\text { Excess }\end{array}$ & $\begin{array}{c}\text { Partially } \\
\text { Accommo- } \\
\text { dative }\end{array}$ & $\begin{array}{c}\text { Conver- } \\
\text { gence } \\
\text { Excess }\end{array}$ & $\begin{array}{l}\text { Partially } \\
\text { Adcommo- } \\
\text { dative }\end{array}$ & \\
\hline $\begin{array}{l}\text { Operation Only } \\
\text { Operation and Orth- } \\
\text { optic Treatment } \\
\text { Orthoptic Treatment } \\
\text { and Glasses } \quad \ldots \\
\text { Glasses Only }\end{array}$ & $\begin{array}{l}23 \\
10\end{array}$ & 4 & $=$ & 1 & 1 & $\begin{array}{l}10 \\
22\end{array}$ \\
\hline \multirow[b]{2}{*}{ Total } & 33 & 13 & 15 & 8 & 5 & \multirow[b]{2}{*}{74} \\
\hline & \multicolumn{3}{|c|}{$61(82 \%)$} & \multicolumn{2}{|c|}{$13(18 \%)$} & \\
\hline
\end{tabular}

(2) Non-Paralytic Non-accommodative ConVergent Strabismus (213 cases: Table III, opposite)

In the non-accommodative group 165 patients had orthoptic treatment, 138 with operation, and 27 without operation. In all cases the visual axes had been made parallel (or approximately so) by operation, except where the deviation was negligible or was corrected by glasses.

Of the total 213 cases, 24 (11 per cent.) regained binocular single vision; in these a favourable result had been envisaged because the average age at onset of squint was $4 \cdot 8$ years.

The remaining 189 cases ( 89 per cent.) were classified as non-binocular. In 116 (61 per cent.), there was no improvement of binocular function and orthoptic treatment proved to be of no value. Had an early and accurate prognosis been made, much time and effort could have been saved in their treatment. (It will be observed that seventy of the 116 patients had orthoptic treatment and an operation, and that fifteen of them had orthoptic treatment only.) In 73 cases (39 per cent.) there was some improvement in binocular function (i.e. normal retinal correspondence was established with doubtful 
TABLE III

NON-PARALYTIC NON-ACCOMMODATIVE CONVERGENT STRABISMUS

\begin{tabular}{|c|c|c|c|c|}
\hline \multirow[b]{2}{*}{ Treatment } & \multirow{2}{*}{$\begin{array}{c}\text { Restoration of } \\
\text { Binocular Single } \\
\text { Vision }\end{array}$} & \multicolumn{2}{|c|}{ Non-Binocular } & \multirow[b]{2}{*}{ Total } \\
\hline & & $\begin{array}{c}\text { Subnormal } \\
\text { Binocular Vision }\end{array}$ & $\begin{array}{l}\text { Defective Binocular } \\
\text { Function* }\end{array}$ & \\
\hline $\begin{array}{l}\text { Operation Only } \ldots \\
\text { Operation and Orthoptic } \\
\text { Treatment } \ldots \\
\text { Orthoptic Treatment Only }\end{array}$ & $\begin{array}{r}8 \\
16 \\
-\end{array}$ & $\begin{array}{r}9 \\
52 \\
12\end{array}$ & $\begin{array}{l}31 \\
70 \\
15\end{array}$ & $\left.\begin{array}{c}48 \\
138 \\
27\end{array}\right\} 165$ \\
\hline \multirow{2}{*}{ Total } & \multirow[b]{2}{*}{$24(11 \%)$} & $73(39 \%)$ & $116(61 \%)$ & \multirow[b]{2}{*}{213} \\
\hline & & \multicolumn{2}{|c|}{$189(89 \%)$} & \\
\hline $\begin{array}{l}\text { Average Age of Patients } \\
\text { (yrs) } \ldots \\
\text { Average Age at Onset of } \\
\text { Squint (yrs) } \ldots \\
\text { Average Time between } \\
\text { Onset of Squint and } \\
\text { Corrective Treatment } \\
\text { (yrs) }\end{array}$ & 1.9 & $6 \cdot 5$ & $\begin{array}{l}5 \cdot 5 \\
1 \cdot 4\end{array}$ & \\
\hline
\end{tabular}

* Severe amblyopia 25 , lack of normal retinal correspondence 73, abnormal retinal correspondence 16 , nystagmus 2 Total 116.

fusion), and it may be concluded that orthoptic treatment may have been of value. These cases have been classified as having "subnormal binocular vision"; they cannot be considered as cured nor should they be regarded as complete failures, for a subnormal form of binocular vision has been established which may result in improvement in visual judgement and may prevent consecutive divergence. Furthermore, it is known that in this type of case binocular single vision may develop spontaneously after a few months or years. The routine re-examination of a series of such cases after an interval of a few years may show that spontaneous recovery is more common than is supposed. The following is an example of such a case:

Case 1, a boy aged 9 years, had a left convergent strabismus which was first noticed at the age of about 5 years. He had had two operations (at the age of 7 years) and orthoptic treatment before attending this hospital.

\section{Examination}

Visual Acuity: Right 6/9; with $+2 \cdot 25 \mathrm{D}$ sph., $+1 \mathrm{D}$ cyl., axis $90^{\circ}, 6 / 6$ and N5.

Left 6/18; with $+3 \mathrm{D}$ sph., $+1 \cdot 75 \mathrm{D}$ cyl., axis $90^{\circ}, 6 / 9$ and N5.

Cover Test: Constant left convergent deviation with and without glasses for both near and distance.

Major Amblyoscope: Angle with glasses $+11^{\circ}, \mathrm{R} / \mathrm{L} 2 \Delta$

Angle without glasses $+13^{\circ}, \mathrm{R} / \mathrm{L} 1 \Delta$

Doubtful fusion.

Treatment: Right medial rectus recession at the age of 11 years.

Post-operative Examination

Visual Acuity: With glasses Right 6/6 and N5; Left 6/6 and N5. 
Major Amblyoscope: Angle with glasses $+2^{\circ}, \mathrm{R} / \mathrm{L} 1 \Delta$

Angle without glasses $+12^{\circ}, \mathrm{R} / \mathrm{L} 1 \Delta$

Doubtful fusion.

Examination 3 years later at the age of 15

Cover Test: Latent convergence for near and distance with glasses.

Constant left convergent deviation without glasses.

Major Amblyoscope: Angle with glasses $+2^{\circ} \ominus$

Angle without glasses $+10^{\circ} \theta$

Fusion and stereoscopic vision present.

In many cases one can reach a decision regarding the prognosis upon the information obtained from the case history (assuming this to be correct). Thus, in the above case, the prognosis was good because the squint did not occur until the age of 5 years (at which age the binocular reflexes are fairly well developed).

The importance of taking a full history cannot be over-emphasized, for it may provide information as to the type of strabismus present, the treatment required, and the likely result of such treatment. Inquiry having been made as to direction of the deviation, whether unilateral or alternating, and whether constant or intermittent, it is important to ascertain:

(a) Age at onset of strabismus,

(b) Mode of onset,

(c) Heredity.

(a) Age at Onset of Strabismus and Duration of Strabismus.-According to Chavasse, the unconditioned binocular reflexes are in a state of flux during the first five years of life, not becoming fully grounded until about the eighth year. Constant interruption of binocular vision by a sensory or motor obstacle will therefore almost invariably result in permanent arrest of their development unless corrective treatment (i.e. the alignment of the visual axes by surgery or by other means) is undertaken at an age when the re-establishment and stabilization of normal binocular function is still possible.

The significance of the age at onset of strabismus is shown in the following case:

Case 2, a girl aged 8 years, had had a mild pyrexia and a "lump" at the side of her neck 5 weeks previously when a sudden and constant right convergent strabismus was noticed.

\section{Examination}

Visual Acuity: Right 6/5 and N5; Lèft 6/5 and N5. No refractive error.

Cover Test: Constant right convergent strabismus.

Ocular Movements: Normal. No relevant refractive error.

Major Amblyoscope: Angle $+18^{\circ} \mathrm{R} / \mathrm{L} 5 \Delta$ fixing with either eye.

Fusion range $+18^{\circ}$ to $+6^{\circ}$, stereopsis present.

Treatment: after 5 months the condition was unchanged and a right medial rectus recession and a right lateral rectus resection were carried out.

\section{Post-operative Examination}

Cover Test: Latent convergence for near with rapid recovery. No deviation for distance. 
Major Amblyoscope: Angle $+5^{\circ} \mathrm{L} / \mathrm{R} 1 \Delta$

Fusion range $+15^{\circ}$ to $-5^{\circ}$, stereopsis present.

The binocular reflexes had become fully grounded before the onset of the strabismus at the age of 8 years. Orthoptic treatment was unnecessary postoperatively as insufficient time had elapsed between the onset of the strabismus and its correction by surgery for deterioration in binocular function to occur.

The following case illustrates how immediate treatment in early childhood may result in a functional cure:

Case 3, a girl aged 4 years, had had a gradual onset of left convergent strabismus noticed at the age of 3 years. At first the deviation was intermittent.

\section{Examination}

Visual Acuity: Right 6/18; with +1.25 D sph., 6/12 and N5.

Left $6 / 18$; with $+1.25 \mathrm{D}$ sph., $6 / 12$ and N5.

Cover Test: Constant alternating convergent strabismus with and without glasses.

Major Amblyoscope: Angle with glasses $+25 / 30^{\circ} \vartheta$

Angle without glasses $+30^{\circ} \vartheta$

Patient too young for assessment of state of binocular vision.

Treatment: (1) Left medial rectus recession, left lateral rectus resection, and (2) right medial rectus recession at the age of 4 years. She attended for twelve sessions of orthoptic treatment post-operatively.

Re-examination: at the age of 6 years the clinical findings were as follows:

Visual Acuity: Right 6/5 and N5; Left 6/6 and N5. No glasses worn.

Cover Test: No deviation for near and distance.

Maddox Rod: Eso $2 \Delta \vartheta$ fixing with either eye.

Maddox Wing: Exo $2 \Delta \vartheta$

Major Amblyoscope: Angle $0^{\circ} \ominus$ fixing with either eye.

Fusion range $+8^{\circ}$ to $-4^{\circ}$, stereopsis present.

In this case the following factors led one to anticipate a good result:

(i) Onset of strabismus comparatively late, i.e. at a time when the binocular reflexes had already undergone normal early development.

(ii) Short duration of the strabismus before the corrective treatment was undertaken which restored parallelism of the visual axes.

(iii) Deviation intermittent at first.

Orthoptic treatment was limited to twelve sessions, sufficient to consolidate the effects of surgery.

The following example shows how loss of binocular vision can become irreparable if the strabismus is of early onset and if corrective treatment is delayed:

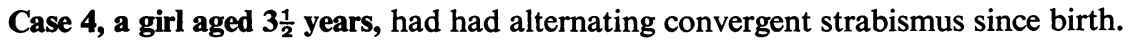

Examination

Visual Acuity: Right 6/24; with $+2.50 \mathrm{D}$ sph., $+0.50 \mathrm{D}$ cyl., axis $90^{\circ}, 6 / 12$ partly. Left $6 / 18$; with $+2 \cdot 50 \mathrm{D}$ sph., 6/12.

Cover Test: Constant alternating convergent strabismus with and without glasses, but prefers to fix with the left eye. 
Major Amblyoscope: Angle with glasses $+25^{\circ} \theta$

Angle without glasses $+32^{\circ} \theta$

Patient too young for assessment of state of binocular vision.

Treatment: Right medial rectus recession, and right lateral rectus resection at the age of $3 \frac{1}{2}$ years. She attended for twelve sessions of post-operative orthoptic treatment.

Re-examination: At the age of 8 years the clinical findings were as follows:

Visual Acuity: Right 6/9 and N5; Left 6/9 and N5. No glasses worn.

Cover Test: Constant right convergent strabismus.

Major Amblyoscope: Angle $+8^{\circ} \vartheta$ fixing with either eye.

Lack of normal retinal correspondence.

Although no time was lost in correcting the strabismus by operation after the child was first brought for examination, the onset of the strabismus at birth and the loss of the vital early years of binocular development had led to a complete loss of binocular vision. The post-operative orthoptic treatment was presumably given in the hope of effecting a functional cure, but in view of the history it was virtually a waste of time.

On the other hand, there are cases in which a spontaneous recovery with binocular single vision occurs post-operatively in spite of a somewhat adverse history and preoperative findings.

Case 5, a boy aged 7 years, had had alternating convergent strabismus since the age of 3 or 4 months. The strabismus was intermittent at first but had become constant by the age of $2 \frac{1}{2}$ years. Glasses prescribed at the age of 4 years did not improve the squint.

\section{Examination}

Visual Acuity: Right $6 / 18$; with $-0.5 \mathrm{D}$ sph., $+1.5 \mathrm{D}$ cyl., axis $90^{\circ}, 6 / 12$.

Left $6 / 12$; with $-0.5 \mathrm{D}$ sph., $+1 \mathrm{D}$ cyl., axis $90^{\circ}, 6 / 9$.

Cover Test: Constant alternating convergent strabismus with and without glasses.

Major Amblyoscope: Angle with glasses fixing right $+42^{\circ} \mathrm{R} / \mathrm{L} 1 \Delta$

Angle with glasses fixing left $+40^{\circ} \mathrm{R} / \mathrm{L} 6 \Delta$

Lack of normal retinal correspondence.

Treatment: (1) Right medial rectus recession, right lateral rectus resection, and (2) left medial rectus recession at the age of 8 years.

Post-operative Examination

Visual Acuity: Right 6/9 and N5; Left 6/9 and N5. With glasses

Cover Test: Constant alternating convergent strabismus with and without glasses.

Major Amblyoscope: Angle with and without glasses fixing right $+12^{\circ} \theta$

$$
\text { fixing left }+10^{\circ} \vartheta
$$

Normal retinal correspondence was present but no fusion.

Re-examination: 3 years later he had binocular single vision and his condition was as follows:

Cover Test: Latent convergence for near and distance with moderate recovery.

Maddox Rod: Fixing right Eso $7 \Delta \vartheta$; fixing left Eso $8 \Delta \vartheta$

Maddox Wing: Eso 5/7 $\diamond$

Major Amblyoscope: Angle $+3^{\circ} \ominus$ fixing with either eye.

Fusion range $+22^{\circ}$ to $0^{\circ}$, stereopsis present.

This case is not exceptional. The history was important. The fact that the squint was intermittent at first and did not become constant until the age of $2 \frac{1}{2}$ 
years was strong evidence that binocular function had been basically good in spite of the lack of normal retinal correspondence and therefore with accurate surgical treatment the prognosis was good.

(b) Mode of Onset.- It is interesting to note that in the 74 cases of accommodative strabismus in which the onset was slow and intermittent, there was a 100 per cent. restoration of binocular single vision. This success is probably also due to the comparatively late average age of onset of the strabismus and the relative ease and rapidity with which the visual axes can be restored to parallelism in most cases (usually by correction of the refractive error).

In many of the non-accommodative cases, the history of the mode of onset was indefinite, and its influence on the final result was therefore inconclusive.

(c) Heredity.-A family history of strabismus is not uncommon in accommodative strabismus and in other types related to the state of refraction. It is also found in the non-accommodative type of convergent strabismus in which there may be an hereditary weakness of one or more of the extrinsic ocular muscles.

Our numbers are too small for conclusive evidence, but a family history of squint was found in 39 per cent. of the accommodative group, and in 41 per cent. of the non-accommodative group. It is interesting to note that an hereditary factor was found more often in the "non-binocular" cases than in those in which binocular single vision was regained.

Defective Binocular Function (116 cases).-Table III shows that 116 patients were discharged with defective binocular function (severe amblyopia, 25; lack of normal retinal correspondence, 73; abnormal retinal correspondence, 16; and latent nystagmus, 2). 85 of these patients had had orthoptic treatment, in seventy cases combined with operation. An analysis of these cases indicates why there was no response to orthoptic treatment:

(a) Amblyopia.-In 54 cases (25 per cent.) of the non-accommodative group, the visual acuity of the squinting eye was less than $6 / 36$ at the first examination. Total occlusion of the fixing eye was carried out in 48 cases, but the remaining six were considered unsuitable for occlusion owing to the relatively mature age of the patients and the early onset of the squint.

After an adequate period of occlusion the 48 cases were classified as follows according to the results obtained:

Group 1.-Twenty cases (41 per cent.), in which equal or nearly equal visual acuity was obtained in each eye.

Group 2.-Nine cases (19 per cent.), in which the visual acuity of the squinting eye improved only to $6 / 18$.

Group 3.-Nineteen cases ( 40 per cent.), in which there was no improvement in the visual acuity of the squinting eye.

There was no great difference between the average age at onset of the strabismus and the average interval between onset and the commencement of occlusion, but the average age of the patients in the first group was 
significantly lower than that of those in the second and third groups. The results of occlusion in these 48 cases are shown in Table IV.

TABLE IV

RESULTS OF OCCLUSION IN 48 CASES OF AMBLYOPIA

\begin{tabular}{|c|c|c|c|}
\hline Visual Acuity after Occlusion & $\begin{array}{c}\text { Average Age } \\
\text { of Patient } \\
\text { (yrs) }\end{array}$ & $\begin{array}{c}\text { Average Age } \\
\text { at Onset of } \\
\text { Strabismus } \\
\text { (yrs) }\end{array}$ & $\begin{array}{c}\text { Average Time } \\
\text { between Onset } \\
\text { of Strabismus } \\
\text { and Occlusion } \\
\text { (yrs) }\end{array}$ \\
\hline 1. Equal or nearly equal & $4 \cdot 9$ & $1 \cdot 6$ & $3 \cdot 3$ \\
\hline $\begin{array}{l}\text { 2. Squinting eye did not improve } \\
\text { beyond } 6 / 18 \quad \ldots \quad \ldots\end{array}$ & $5 \cdot 5$ & $2 \cdot 1$ & $3 \cdot 0$ \\
\hline 3. Squinting eye did not improve & $5 \cdot 7$ & $1 \cdot 5$ & $3 \cdot 1$ \\
\hline
\end{tabular}

Thus amblyopia which did not respond adequately to occlusion certainly accounted for 25 cases and probably also for an additional nine cases in which there was failure to restore binocular single vision. The desirability of carrying out occlusion as early as possible is emphasized by this analysis.

We have not yet had any experience of the treatment of amblyopia by the after-image method of Cüppers. This method appears to offer great possibilities for the improvement of vision in cases of suppression amblyopia, especially those associated with eccentric fixation.

(b) Lack of Normal Retinal Correspondence.-73 patients showed lack of normal retinal correspondence; 45 of them had orthoptic treatment (combined with operation in 41 cases) and in no case was there any improvement in binocular function. 28 patients had surgical treatment without any orthoptic treatment. The age and time factors are much the same both in those patients who had orthoptic treatment and those who did not (Table V).

TABLE V

PATIENTS WITH LACK OF NORMAL RETINAL CORRESPONDENCE

\begin{tabular}{|c|c|c|c|}
\hline Treatment & Operation Only & $\begin{array}{c}\text { Orthoptic Treatment } \\
\text { + Operation in } 41 \text { Cases })\end{array}$ & Total \\
\hline $\begin{array}{lll}\cdots & \cdots & \ldots\end{array}$ & 28 & 45 & 73 \\
\hline 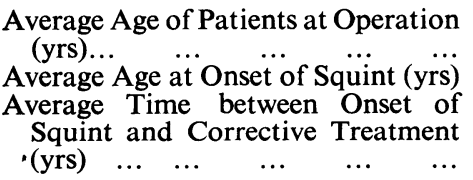 & $\begin{array}{l}5 \\
1\end{array}$ & $\begin{array}{l}5 \cdot 7 \\
1 \cdot 7\end{array}$ & \\
\hline
\end{tabular}

The average age at onset of squint in the patients in this group is notably early. It seems quite clear that in these cases pre-operative orthoptic treatment is useless and it is also doubtful whether post-operative orthoptic treatment is of any value. 
(c) Abnormal Retinal Correspondence.-This was present in only sixteen ( 8 per cent.) of the 213 cases of non-accommodative convergent strabismus.

The differentiation between a definite abnormal retinal correspondence and a lack of normal retinal correspondence with a tendency towards anomalous correspondence requires careful clinical investigation. In the former condition, when tested on a major amblyoscope, the patient "puts the lion into the cage" at an angle less than the objective angle of deviation; a small range of fusion on non-corresponding points of the retinae is usually present, and the response to the after-image test is consistently abnormal. In the latter condition, the patient attempts to "put the lion into the cage" at an angle differing from the true angle of deviation (as measured objectively), but is unable to do so on account of suppression; there is no range of fusion and the response to the after-image test may be normal or abnormal.

In this series, only cases with a definite angle of anomaly and a small range of fusion have been classified as showing abnormal retinal correspondence.

It is not possible to draw any definite conclusions from so small a number, but of the sixteen cases of abnormal retinal correspondence in which orthoptic treatment was carried out (ten combined with operation) not one developed normal retinal correspondence. The time spent in striving to achieve normal retinal correspondence seems to be fruitless, especially since it is now generally believed that true abnormal retinal correspondence is a perverted form of binocular single vision and has a relative stability. Post-operative consecutive divergence is less likely to occur in this condition than in cases in which the perversion has not become strongly established. It should be mentioned, however, that in the past abnormal retinal correspondence was much more loosely defined, and that cases alleged to have been cured by surgical and orthoptic treatment were probably examples of lack of normal retinal correspondence.

The essential age and time factors in the history of the sixteen cases of abnormal retinal correspondence are somewhat similar to those of the 73 patients with lack of normal retinal correspondence (Table VI).

TABLE VI

PATIENTS WITH ABNORMAL RETINAL CORRESPONDENCE

\begin{tabular}{|c|c|c|c|}
\hline Treatment & Operation Only & $\begin{array}{c}\text { Orthoptic Treatment } \\
\text { (+ Operation in } 10 \text { Cases) }\end{array}$ & Total \\
\hline No. of Patients $\quad \ldots \quad \ldots \quad \quad \ldots$ & 1 & 15 & 16 \\
\hline $\begin{array}{l}\text { Average Age of Patients (yrs) } \\
\text { Average Age at Onset of Strabismus } \\
\text { (yrs)... } \ldots \text {... } \ldots \text {... } \\
\text { Average Time between Onset of } \\
\text { Strabismus and Corrective Treat- } \\
\text { ment (yrs) } \ldots \quad \ldots \quad \ldots \quad \ldots \quad \ldots\end{array}$ & $\begin{array}{r}11 \\
2\end{array}$ & $\begin{array}{l}6 \cdot 7 \\
1 \cdot 4\end{array}$ & \\
\hline
\end{tabular}


(d) Latent Nystagmus.-Cases in which gross latent nystagmus is associated with convergent strabismus need no special comment. Defective binocular function or binocular instability is invariably present.

Subnormal Binocular Vision ( 73 cases).-By studying the history of the case, taking the age of the patient into consideration, and making a few simple tests, it should not be difficult to differentiate between patients who are likely to regain full binocular single vision, either by operation alone or with the aid of orthoptic treatment and occlusion if necessary, and those who are unlikely to attain binocular vision.

There is however an intermediate group which consists of those who improve to the extent of regaining equal or nearly equal visual acuity, normal retinal correspondence, and doubtful fusion. These patients may benefit from the improved visual judgment which they thereby gain, and, providing the angle of deviation is small, they may develop binocular single vision spontaneously with the passage of time. This group may indeed be considerably helped by orthoptic treatment; 73 of the 213 cases of nonaccommodative convergent strabismus belonged to this group.

In comparing these with the 116 cases with defective binocular function, Table III shows that, although, as one would expect, the average age at onset of strabismus was lower in the patients with defective binocular function, the average interval between the onset of strabismus and the commencement of corrective treatment was slightly shorter.

It is perhaps significant that, of the 73 cases with subnormal binocular vision, 21 (30 per cent.) already had normal retinal correspondence before treatment started, and five ( 7 per cent.) were too young for an accurate assessment of the state of binocular vision. At the first examination the remaining 47 patients (63 per cent.) had no binocular vision, either through gross amblyopia or lack of normal retinal correspondence. (There were no cases of abnormal retinal correspondence in this group.)

The average age at onset of strabismus was $2 \cdot 2$ years in patients with subnormal binocular vision, compared with 1.4 years in the patients with defective binocular function who did not respond to treatment. The average interval between the onset of the strabismus and the commencement of corrective treatment was 4 years and 3.5 years respectively, and the average age of the patient when treatment was begun was 6.5 and 5.5 years respectively (Table III).

Since there appears to be no outstanding difference in the general trend of the history of the two groups, it may be that in some cases, although the loss of normal binocular vision seems apparent pre-operatively, surgical correction of the strabismus may induce a return of weak binocular vision which had already existed before the onset of the strabismus.

In seven cases normal retinal correspondence developed spontaneously after operation. 
Vertical Factor in Convergent Strabismus.-In fifty (24 per cent.) of the 213 nonaccommodative cases there was a primary vertical deviation due to defective action of one or more of the vertically acting muscles. Unlike certain cases of convergent strabismus in which there is over-elevation of the non-fixing eye on adduction which becomes rectified when the horizontal deviation is corrected, in these cases surgical correction of the horizontal deviation fails to reduce the vertical deviation. Thus, if binocular single vision is to be expected, operation on the vertically acting muscles becomes necessary.

The history of these cases appears to be similar to that of the cases with a purely horizontal deviation and the results as regards binocular function are also similar.

Follow-up Investigations. - Of the 213 cases of non-paralytic non-accommodative convergent strabismus under investigation, ninety were re-examined 3 years after discharge from the orthoptic department in order to find out if there was:

(i) Any deterioration of binocular function.

(ii) Any improvement of binocular function.

(iii) Any evidence of consecutive divergence.

These cases were chosen at random and comprised the following:

6 discharged with binocular single vision.

34 discharged with subnormal binocular vision.

50 discharged with defective binocular function.

The essential facts are set out in Table VII:

TABLE VII

CONDITION OF PATIENTS

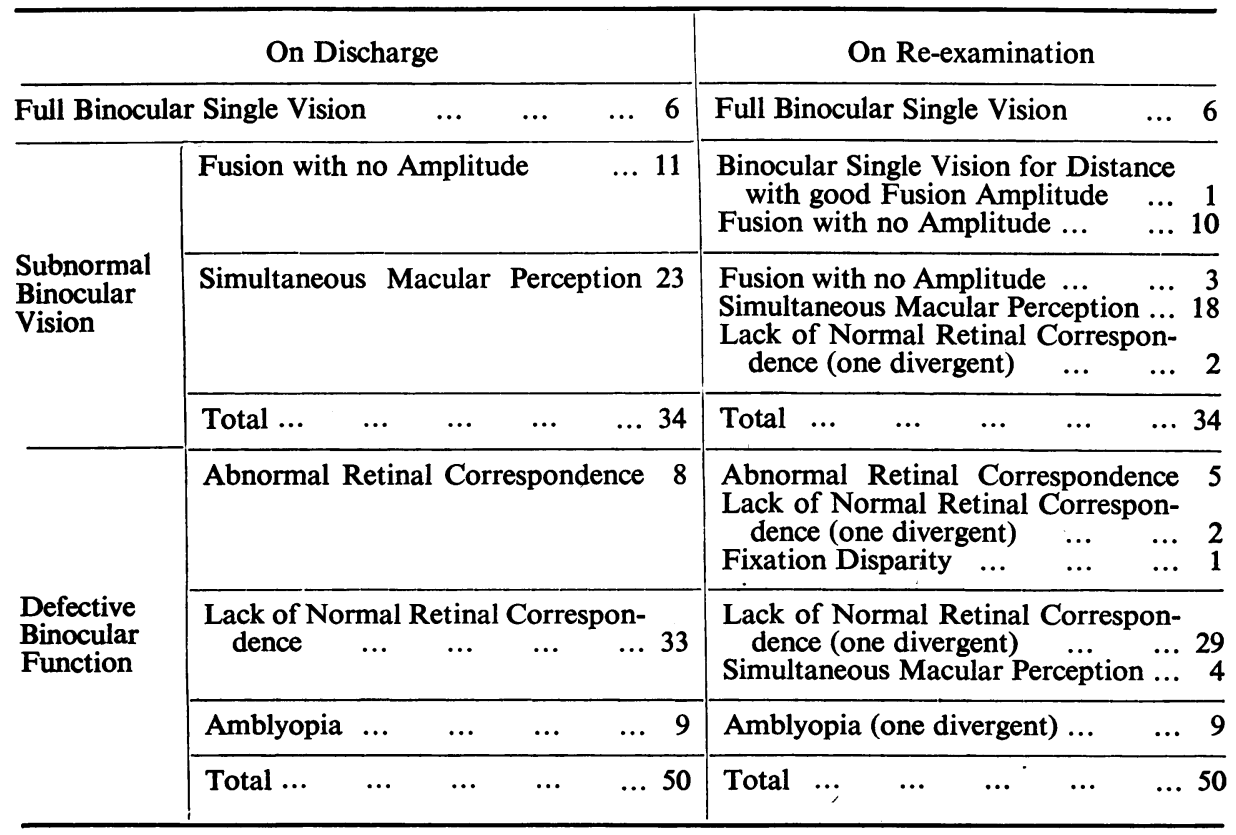


Of the 34 cases discharged with subnormal binocular vision, there was no change in binocular function in 28 , but consecutive divergence was present in one case. In four cases there had been an improvement in binocular function to the extent of restoration of binocular single vision for distance in one case. There was however, little evidence in the history of these cases to suggest the likelihood of an improvement of binocular function in the passage of time except in one case in which the age of onset of the strabismus was said to be 5 years.

There was no improvement in binocular function in 45 of the fifty cases with defective binocular vision. Consecutive divergence was present in three cases. Four patients who originally had lack of normal retinal correspondence had developed normal retinal correspondence, and one patient with abnormal retinal correspondence had developed fixation disparity. Here again there was no indication in the history leading one to anticipate an improvement in binocular function. It is not, however, possible to draw conclusions as to the probability of further spontaneous improvement of binocular function in so few cases.

We have seen that, in the non-accommodative type of convergent strabismus, the chances of restoring full binocular single vision are remote unless the strabismus is of later onset (i.e. after about the 2nd year when the binocular reflexes are fully or partially developed) and is speedily dealt with before deterioration of binocular function can take place. The importance of orthoptic treatment in the re-education of normal binocular function should not be under-estimated in cases in which the history and clinical findings show that this is potentially possible, and careful consideration before undertaking treatment should lead to considerable lessening of unnecessary work.

\section{Primary Divergent Strabismus}

In dealing with divergent strabismus we have included adult patients, since especially in intermittent divergence, the patient may not suffer from symptoms until adult life. Early treatment in childhood is however to be recommended.

A consecutive series of 121 cases of divergent strabismus has been studied. The cases were divided into two main groups:

(1) Constant Divergent Strabismus.-This may date from birth or earliest infancy. Binocular vision is frequently lost.

(2) Intermittent Divergent Strabismus.-The intermittent nature of the squint ensures that normal binocular function is preserved. In neglected cases the deviation may in time become constant with deterioration of binocular function.

(1) Constant Divergent Strabismus (29 cases)

The average age of the patients in this group was 29 years, the average 
age at onset of strabismus was 2 years, and the average interval between the onset of squint and corrective treatment was 23.7 years. Weak fusion was demonstrable in three cases pre-operatively. In the remaining 26 cases, gross amblyopia was present in nine and complete loss of binocular vision in seventeen.

In nine cases binocular single vision was restored post-operatively. In three of these fusion could not be demonstrated immediately after operation, but the deviation appeared to be latent with an apparent recovery to binocular fixation as shown by the cover test. Of the other six cases in which binocular single vision developed, two showed weak fusion pre-operatively and four showed complete loss of binocular vision. In the two cases discharged with an intermittent deviation there was little amplitude of fusion and no stereopsis. In a follow-up examination 3 years later, re-divergence had occurred in one of these cases with deterioration of binocular function.

Post-operative spontaneous development of normal binocular function in cases in which there is no pre-operative evidence of normal retinal correspondence is not uncommon in divergent strabismus as the following case exemplifies:

Case 6, a woman aged 29, had had left divergent strabismus probably since birth, which became more noticeable after fits during teething.

\section{Examination}

Visual Acuity: Right 6/36; with $-2 \cdot 5 \mathrm{D}$ sph., $-2 \cdot 25 \mathrm{D}$ cyl., axis $100^{\circ}, 6 / 5$ and N5. Left $6 / 60$; with $+1 \mathrm{D}$ sph., $-4 \mathrm{D}$ cyl., axis $50^{\circ}, 6 / 24$ and N8.

Cover Test: Constant left divergent strabismus.

Major Amblyoscope: Angle fixing right $-34^{\circ} \mathrm{R} / \mathrm{L} 2 \Delta$

Angle fixing left $-33^{\circ} \mathrm{L} / \mathrm{R} 2 \Delta$

No subjective angle obtained.

Treatment: (1) Left lateral rectus tenotomy and left medial rectus resection. (2) Right medial rectus marginal myotomy (on account of slight overcorrection) and right inferior rectus marginal myotomy.

Post-operatively the deviation was latent and, although simultaneous macular perception was present, fusion was still not demonstrable on the major amblyoscope.

A routine examination 2 years later revealed that since the operation binocular single vision with a good range of fusion and stereopsis had developed and the vision of the left eye had improved from 6/24 to 6/9:

\section{Re-examination}

Visual Acuity: Right 6/5 and N5; Left 6/9 and N5. With glasses.

Cover Test: Moderate latent divergence for near and distance with rapid recovery.

Major Amblyoscope: Angle fixing right $-4^{\circ}$ R/L $3 \Delta$

Angle fixing left $-6^{\circ} \mathrm{R} / \mathrm{L} 1 \Delta$

Fusion range $+8^{\circ}$ to $-6^{\circ}$, stereopsis present.

Maddox Rod: Fixing right Exo $7 \Delta$ R/L $2 \Delta$

Fixing left Exo $9 \Delta \mathrm{R} / \mathrm{L} 2 \Delta$ 
(2) INTERMittent Divergent Strabismus (92 cases)

These cases have been divided into the following groups:

(a) Divergence Excess (43 cases: Maddox rod reading exceeds Maddox wing reading).

(b) Convergence Weakness (24 cases: Maddox wing reading exceeds Maddox rod reading).

(c) Mixed (25 cases: Maddox rod and wing reading approximately the same). These cases are probably originally of the divergence excess type with secondary convergence weakness.

Binocular single vision is maintained either for near (divergence excess type) or for distant vision (convergence weakness type), although in neglected cases the deviation may become constant. The age at onset of the strabismus is often indefinite, varying from birth to adolescence, and in this series averages 4.5 years. The interval between the onset of strabismus and the beginning of corrective treatment is correspondingly indefinite and averages 10.9 years. In general, intermittent divergent strabismus of the divergence excess type starts at an earlier age than that of the convergence weakness type.

Diplopia and other symptoms resulting from the voluntary effort to maintain binocular single vision are common, but in some cases suppression may be intense, making the patient unaware of his squint. The intermittent nature of the strabismus renders it amenable to orthoptic treatment although surgical treatment is invariably necessary to effect a complete cure, with the possible exception of certain cases of the convergence weakness type in which there is sometimes relief of symptoms from orthoptic treatment alone. Controversy still exists over the age at which operation should be performed. Some people disapprove of surgical treatment in childhood believing that the normal development of the face during the years of growth will cause redivergence later. In this series, 21 children were operated on before the age of 10 years; in fourteen of these full binocular single vision was restored, four patients still had some intermittent deviation at times, and three who had weak or doubtful fusion pre-operatively were discharged with constant convergence and no fusion. During a follow-up examination 3 years later, seven of the fourteen patients who were discharged with binocular single vision and no deviation were re-examined, and their condition was found to be exactly the same. One patient discharged with a constant convergent deviation and no fusion was showing a tendency to re-divergence.

The prognosis in primary divergent strabismus therefore depends mainly on the type of onset, i.e. whether it is intermittent or constant. In almost all cases in which the deviation is originally intermittent, binocular single vision can be restored, despite the fact that through neglect the divergence may have subsequently become constant with deterioration of binocular function. Orthoptic treatment is often of value in helping the restoration of binocular function. 
If a divergent strabismus is constant from the beginning, especially if the condition started within the first 2 years of life, the prognosis is usually poor, although in a few cases binocular single vision may be restored spontaneously after operation, provided the visual axes are restored to parallelism.

\section{(B) CONGENITAL PARALYTIC STRABISMUS}

A patient with a congenital paralytic strabismus may be able to preserve a full or partial field of binocular single vision by adopting a compensatory head posture and/or by possessing an abnormally large vertical fusion range. Thus the condition may sometimes remain compensated throughout life On the other hand symptoms of decompensation may occur in adult life, and if untreated an intermittent squint may gradually give place to a constant deviation. In some cases of paralytic strabismus of severe degree there may be a complete loss of binocular vision from earliest infancy. With the exception of the latter cases, the prognosis in congenital paralytic strabismus is invariably good and depends upon surgical rather than orthoptic treatment, but careful orthoptic investigation provides useful information as to the surgical treatment required.

Our series of 107 patients are divided into two groups:

I. Patients with no binocular vision.

II. Patients whose binocular vision has been maintained.

\section{Patients with No Binocular Vision (15 cases)}

These fifteen patients have been classified as follows:

(1) Palsy of Horizontally-Acting Muscles (3).

(a) Duane's retraction syndrome (2).

(b) Moebius' syndrome (1).

(2) Palsy of Vertically-Acting Muscles with Secondary Convergence (7).

(a) Convergent strabismus with palsy of an elevator or depressor muscle of one eye.

(b) Convergent strabismus with palsy of both elevators of one eye (1).

(c) Convergent strabismus with mixed or multiple palsy (2).

(3) Palsy of Vertically-Acting Muscles with Secondary Divergence (5).

(a) Divergent strabismus with palsy of both depressor muscles of one eye (1).

(b) Divergent strabismus with mixed or multiple palsy (4).

Treatment consisted only of operation to improve the cosmetic appearance. Orthoptic treatment was not given in any case.

\section{Patients whose Binocular Vision has been Maintained}

(92 cases)

Binocular single vision was maintained by the adoption of a compensatory head posture in fifty (54 per cent.), and in the remaining 42 (46 per cent.) the deviation was partly controlled and partial or full binocular single vision 
was obtained, the head posture being normal. Subjective symptoms occurred in 35 ( 73 per cent.) of the patients with a compensatory head posture, and in 38 (86 per cent.) of the patients without a compensatory head posture. The average age of the patients with symptoms was 33 years, and of those without symptoms was 14 years.

(1) Palsy of Horizontally-Acting Muscles (16 cases: Table VIII).-The following muscles were involved:

Lateral rectus (9).

Lateral rectus associated with Duane's retraction syndrome (6).

Medial rectus (1).

TABLE VIII

PALSY OF HORIZONTALLY-ACTING MUSCLES IN SIXTEEN CASES

\begin{tabular}{|c|c|c|}
\hline $\begin{array}{l}\text { Subjective } \\
\text { Symptoms }\end{array}$ & $\begin{array}{l}\text { Present } \ldots \\
(5 \text { with } \\
\text { posture) }\end{array}$ & $\begin{array}{c}\text { Absent } \\
\begin{array}{c}(4 \text { with } \\
\text { posture })\end{array}\end{array}$ \\
\hline \multirow[t]{2}{*}{$\begin{array}{l}\text { Post-Operative } \\
\text { Result }\end{array}$} & $\begin{array}{l}\text { Binocular Single Vision } \\
\text { Symptom-free } \quad \ldots . \\
\text { (head posture normal) }\end{array}$ & $\begin{array}{l}\text { Binocular Single Vision ... ... } \\
\text { (3 originally with compensatory } \\
\text { head posture now normal) } \\
\text { Still some Intermittent Deviation } \\
\text { (1 with compensatory head } \\
\text { posture unchanged) }\end{array}$ \\
\hline & Total $\ldots$ & $\begin{array}{lll}\ldots & \ldots & \ldots\end{array}$ \\
\hline
\end{tabular}

Eight adult patients complained of symptoms pre-operatively. All were symptom-free after operation.

Of the eight patients (six adults and two children aged about 7) who had no subjective symptoms, six were discharged as satisfactory post-operatively. Three of these (the two children and one adult) originally had a compensatory head posture which disappeared after surgical correction of the paresis. Two adult patients improved but still showed an occasional deviation. One of these had a compensatory head posture which remained unchanged.

Orthoptic treatment was not considered necessary in any of these cases.

(2) Palsy of Vertically-Acting Muscles (76 cases)

(a) Palsy of Vertically-Acting Muscles unassociated with a Horizontal Deviation (63 cases: Table IX): The following muscles were involved:

$\begin{array}{lr}\text { Superior rectus } & 31 \\ \text { Superior oblique } & 25 \\ \text { Inferior oblique } & 5 \\ \text { Inferior rectus } & 2\end{array}$

55 patients complained of symptoms pre-operatively. 51 of these were completely relieved of their symptoms after surgical correction of the palsy and in the remaining four cases symptoms were much improved. 
Of the eight patients who had no subjective symptoms, seven were discharged with binocular single vision. One child still had some intermittent deviation and may require further operation.

A compensatory head posture was present in thirty cases and became normal in 29 cases (Table IX). In four cases binocular function had deteriorated despite the presence of a compensatory head posture, but after operation full binocular function was restored spontaneously.

TABLE IX

PALSY OF VERTICALLY-ACTING MUSCLES IN 63 CASES

(Unassociated with a Horizontal Deviation)

\begin{tabular}{|c|c|c|}
\hline $\begin{array}{l}\text { Subjective } \\
\text { Symptoms }\end{array}$ & $\begin{array}{l}\text { Present } \ldots \ldots \ldots \ldots \\
(23 \text { with } \\
\text { posture) }\end{array}$ & 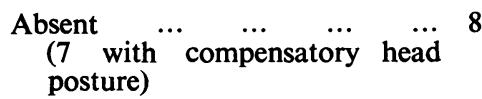 \\
\hline \multirow[t]{2}{*}{$\begin{array}{l}\text { Post-Operative } \\
\text { Result }\end{array}$} & \begin{tabular}{cccccc}
\multicolumn{2}{l}{ Binocular Single Vision } & \multicolumn{3}{c}{ Symptom- } \\
$\quad$ free & $\ldots$ & $\ldots$ & $\ldots$ & $\ldots$ & 51 \\
Symptoms Improved & $\ldots$ & $\ldots$ & 4
\end{tabular} & $\begin{array}{l}\begin{array}{l}\text { Binocular Single Vision } \ldots \\
\quad \text { one with compensatory head }\end{array} \\
\quad \text { posture unchanged) } \\
\text { Still some Intermittent Deviation }\end{array}$ \\
\hline & $\ldots \quad \ldots 55$ & Total \\
\hline
\end{tabular}

(b) Palsy of Vertically-Acting Muscles with Secondary Divergence (9 cases).-The following muscles were involved:

$\begin{array}{ll}\text { Superior rectus } & 7 \\ \text { Superior oblique } & 1 \\ \text { Inferior rectus } & 1\end{array}$

Eight patients complained of symptoms pre-operatively. Six were symptom-free after operation and symptoms were considerably improved in the remaining two cases. Five of these eight patients had a compensatory head posture before operation which disappeared after operation in three cases.

One child who had no symptoms but had a compensatory head posture with good binocular function was discharged with binocular single vision and a normal head posture.

(c) Palsy of Vertically-Acting Muscles with Secondary Convergence (4 cases).-The following muscles were involved:

$\begin{array}{ll}\text { Superior rectus } & 3 \\ \text { Superior oblique } & 1\end{array}$

Two patients had symptoms, both with a compensatory head posture. One of these patients had good binocular function and the symptoms were relieved post-operatively with a return to a normal head posture. In the other case (a child aged 6 years) the deviation was constant pre-operatively 
in spite of the presence of a compensatory head posture, but binocular single vision was restored after operation although the head posture remained abnormal.

The two patients who had no symptoms (aged 4 and 7 years respectively) both had a compensatory head posture and good binocular function preoperatively. Full binocular single vision and a normal head posture were restored post-operatively.

\section{SUMMARY AND CONCLUSION}

It has been our aim in this article to stress the value of orthoptic treatment in cases in which it is justified and to emphasize that the time that is often spent in giving orthoptic treatment when it is not justified is time wasted. Great care should be taken in the selection of patients suitable for orthoptic treatment, particularly in the case of non-paralytic non-accommodative convergent strabismus.

The results in 213 cases of this type have been divided into three categories (Table III):

(1) Restoration of binocular single vision: 24 cases (11 per cent.)

(2) Subnormal binocular vision (equal or nearly equal visual acuity, normal retinal correspondence, doubtful fusion):

(3) Defective binocular function (intractable amblyopia, lack of normal retinal correspondence, abnormal retinal correspondence, latent nystagmus):

116 cases (61 per cent.)

165 (77 per cent.) of these patients had orthoptic treatment (combined with operation in 138 cases) and the results correspond with those mentioned above:

(1) Restoration of binocular vision:

16 cases $(10$ per cent.)

(2) Subnormal binocular vision: 64 cases ( 39 per cent.)

(3) Defective binocular function: 85 cases (51 per cent.)

48 ( 23 per cent.) of these patients had no orthoptic treatment and in these results appear to be slightly better as far as Category 1 is concerned:

(1) Restoration of binocular single vision:

8 cases (17 per cent.)

(2) Subnormal binocular vision:

(3) Defective binocular function:

9 cases (19 per cent.)

31 cases (64 per cent.)

It is not suggested that a decision regarding the prognosis can always be made at the first visit, for in many instances, particularly in the case of young children, several diagnostic sessions may be necessary, but an early prognosis 
concerning the anticipated standard the patient will reach in terms of binocular function should help to eliminate much unnecessary and unrewarding work and allow more time for concentrated treatment in deserving cases.

A study of the history in convergent strabismus shows that with few exceptions the results depend on the following factors:

(a) The age of the patient.

(b) The age at onset of strabismus.

(c) The mode of onset of the strabismus (i.e. constant from onset or intermittent).

(d) The duration of the strabismus before the visual axes are aligned by operation or other means.

Given the necessary data from the case history and from clinical investigation, and having decided upon the standard of binocular function which the patient is likely to regain, treatment can then be limited to achieving this end. Thus it should no longer be necessary to "try" orthoptic treatment. Orthoptic treatment is either indicated or it is not indicated. It is indicated only if there is a reasonable chance of thereby helping the patient to acquire some useful form of binocular vision. It is not indicated if there is clearly no chance of achieving any useful form of binocular vision.

The conclusions regarding prognosis and treatment that may be drawn from a study of the cases analysed in this article are summarized below.

\section{PROGNOSIS AND TREATMENT INDICATED IN STRABISMUS}

(With regard to binocular single vision)

\section{(A) NON-PARALYTIC STRABISMUS}

(1) Accommodative

\section{Convergent Strabismus}

(a) Fully Accommodative.-Prognosis, binocular single vision. Treatment, correction of refractive error, operation rarely needed.

(b) Convergence Excess.-Prognosis, binocular single vision. Treatment, correction of refractive error and in some cases operation.

(c) Partially Accommodative.-Prognosis, binocular single vision. Treatment of refractive error and operation.

Orthoptic treatment may be valuable in all types.

(2) Non-ACCOMMODATIVE

\section{(a) Of Early Onset}

(Birth to 18 months).--Rarely any chance of binocular single vision except in certain cases in which the visual axes have been made approximately parallel by operation within the first 2 or $2 \frac{1}{2}$ years of life.

(b) Of Later Onset

( 2 to 3 years).-Binocular vision of a subnormal type may develop, provided the visual axes have been made approximately parallel, and orthoptic treatment may be of great value in obtaining it. Subnormal binocular vision may gradually be superseded by full binocular single vision. 


\section{(c) Of Late Onset}

( 3 to 5 years or later).--Normal binocular single vision should result following operation even if the latter is postponed until later in childhood or even early adult life provided adequate orthoptic supervision ensures equal visual acuity, absence of suppression etc.

\section{Notes}

(i) In non-accommodative convergent strabismus in which there is a vertical factor, the prognosis is no worse provided that the vertical deviation is adequately overcome by operation.

(ii) In any case of convergent strabismus in a child, provided there is good vision in each eye and provided that the angle of deviation is overcome by appropriate treatment, there is always a chance (even if a remote one) that some form of binocular vision may result.

(iii) If the strabismus is purely intermittent the prognosis is good.

\section{Primary Divergent Strabismus}

In general the prognosis is good even when the deviation is constant, (provided there is good visual acuity in each eye) for in many cases the strabismus has started in an intermittent fashion. Operation is needed in most cases but in some cases of intermittent divergent strabismus orthoptic treatment alone may suffice. The correction of the refractive error if myopic or astigmatic and the correction of anisometropia may be of great value.

\section{(B) CONGENITAL PARALYTIC STRABISMUS}

If binocular functions are good, even if binocular single vision is not demonstrable in any position of the gaze, the prognosis is good provided the surgical treatment is adequate. The existence of an abnormal head posture of the type that would be expected in the particular ocular palsy present indicates that binocular single vision has probably been present previously, and even if binocularity no longer exists the chance of its restoration by adequate surgical treatment (aided by orthoptic treatment) is good.

If binocular vision is absent the prognosis is usually poor unless surgical treatment is carried out at an early age.

In cases of strabismus where normal binocular function is thought to have existed previously (even if in rudimentary form) or is thought to exist potentially, the value of orthoptic treatment as a re-educating process is already known, but the application of our knowledge to the effects of disturbances of reflex development on the squinting child is still in the experimental stage. The restriction of orthoptic treatment to those cases in which there is a reasonable chance of improving binocular function would lessen much of the time-consuming work undertaken in an orthoptic clinic, and allow more time to be spent upon the detailed investigation and diagnosis of cases, especially those in which surgical treatment is required.

\section{REFERENCE}

Chavasse, F. B. (1939). “Worth's Squint”, 7th ed. Baillière, Tindall and Cox, London. 